\title{
The Lived Experiences of Fibromyalgia in Taiwanese Women
}

\author{
Shih, Whei-Mei
}

RN, PhD. Associate Professor, Graduate Institute of Health Care, Chang

Gung University of Science and Technology, KweiShan, Taiwan.

\section{Tsao, Lee-Ing}

RN, DNSc, Professor, Nursing department and Graduate School, National

Taipei University of Nursing and Health Sciences, Taipei, Taiwan.

\section{Hsu, Hsiu-Chin}

$\mathrm{RN}, \mathrm{PhD}$. Assistant Professor, Graduate Institute of Health Care, Chang Gung University of Science and Technology, KweiShan, Taiwan.

\section{Hsiao, Pin-Ru}

$\mathrm{RN}, \mathrm{PhD}$. Assistant Professor, Nursing Department, Chang Gung University of Science and Technology, ChiaYi, Taiwan.

Doi: 10.19044/esj.2018.v14n18p49 URL:http://dx.doi.org/10.19044/esj.2018.v14n18p49

\begin{abstract}
Fibromyalgia is characterized by chronic widespread musculoskeletal pain and associated symptoms. It affects people physically, mentally, and socially. The aim of this study was to explore the life experience of women with fibromyalgia in order to gain knowledge which can contribute to increased quality of healthcare. In-depth interviews were used to collect information from nineteen Taiwanese women who were diagnosed with fibromyalgia. Data were analyzed using the content analysis approach. Data analysis revealed four categories: life torture by physical suffering, torment of the mind, treatment seeking, and facing an incurable and unknown illness alone. Each category was described in terms of its properties and subcategories. This article provides information to fibromyalgia patients who suffer from severe chronic pain and related discomforts. Recommendations focus on helping women with fibromyalgia achieve or maintain integrity especially in the conservative oriental people. It is beneficial for both health care professionals and patients.
\end{abstract}

Keywords: Fibromyalgia, qualitative research, chronic pain 


\section{Introduction}

Fibromyalgia (FM) is a common and complex chronic pain disorder with fluctuating musculoskeletal pain as the main symptom. It affects people physically, mentally, and socially that occurs in the absence of a clear pathologic cause (Walitt, Katz, Bergman, \& Wolfe, 2016; Wolfe, Brähler, Hinz, \& Häuser, 2013). Fibromyalgia is not a disease but a syndrome of unknown origin and multiple symptoms.

Currently there are no objective tests available and a lack of abnormal symptoms found upon physical examination limit diagnosing FM. Laboratory tests often prove negative and many FM symptoms overlap with those of other conditions such as arthritis or osteoporosis. This can lead to extensive investigative costs and frustration for both the doctor and patient. Doctors must rely on a patient history, self-reported symptoms, a physical examination, and an accurate manual tender point examination (D. L. Goldenberg, 1995; Wolfe, 2009). The 2011 modification for survey research of the American College of Rheumatology (ACR) Preliminary Diagnostic Criteria for Fibromyalgia has enabled investigators to approximate both fibromyalgia diagnosis and severity outside of the clinical setting (Wolfe et al., 2011; Wolfe et al., 2010) It is estimated that it takes an average of five years for an FM patient after they start experiencing symptoms to be diagnosed (D. L. Goldenberg, 1995). Therefore, the challenges of FM management reinforce the need to gain more understanding of how FM influences a patient with this syndrome. In this qualitative study, we explored the experiences of women with FM in order to gain knowledge which can contribute to quality care.

The prevalence of FM is approximately1.75\% and more than $90 \%$ of those diagnosed are women (Walitt, Nahin, Katz, Bergman, \& Wolfe, 2015; Wolfe et al., 2013). Demographic and social characteristics associated with the presence of FM are female, divorced, low income, and no high school diploma. Psychological factors associated with this syndrome include: somatization disorder, anxiety, and personal or family history of depression (Gota, Kaouk, \& Wilke, 2015). In Taiwan, the prevalence of FM was $6.7 \%$ and $9.8 \%$ based on the population of one small town in the middle of Taiwan which was higher than nearby countries such as Korea (1.7\%-2.3\%) and Japan (0.51-2.04\%) (Chen, Guo, You, Liaw, \& Kuo, 2008; Kim, Kim, \& Kim, 2012; Nakamura et al., 2014; Toda, 2007).

Over five years, the total cost for FM-related care increased $\$ 163.2$ million. Health care utilization was higher for FM cases compared to irritable bowel syndrome cases (Chandran et al., 2012). The costs associated with FM treatment attempts are relatively expensive to both the individual and society. According to different reports, the annual costs may vary from $\$ 3,813$ (USD) to $\$ 7,973$ for direct costs and $\$ 720$ to $\$ 10,697$ for indirect costs. The total costs 
being $\$ 4,533$ to $\$ 18,670$. The direct costs include physician office visits, diagnostic tests, prescription medications, emergency room visits, and out-ofpocket costs incurred by subjects for FM treatments and home healthcare services. The indirect costs are related to missing work and/or to disability due to FM, including both disability payments and the cost of unemployment. These figures do not include additional substantial indirect costs related to FM, which may include a reduction in work schedule or early retirement, as well as lost productivity for caregivers. The total annual cost for FM claimants was more than twice as high as the cost for the typical insurance beneficiary and the prevalence of disability among employees with FM was twice as high as among all employees(D. Goldenberg, Schaefer, Ryan, Chandran, \& Slateva, 2009; Wassem \& Hendrix, 2003).

Pain at multiple body sites, fatigue, physical disabilities, and poor sleep are major complaints in FM patients, which impacts their lives. Other common symptoms associated with FM include varying degrees of anxiety and depression, problems with memory and concentration, and a decreased sense of energy. Furthermore, certain other medical conditions are commonly associated with FM, such as irritable bowel syndrome, overactive bladder, tension headaches, migraines, cold intolerance, restless leg syndrome, dry eyes and mouth, balance problems, and ringing in the ears (Robert M. Bennett, Jones, Turk, Russell, \& Matallana, 2007; Giesecke et al., 2003; Walitt et al., 2015).

Most FM patients have been through the medical mill. They have frequently undergone extensive tests to try to identify a cause for their chronic illness. Patients, families, and the medical profession have had to reconcile an outwardly healthy-looking body with complaints that are subjective, and at times severe. Since there are no confirmatory tests, as well as a poor response to pharmacological intervention (R. M. Bennett et al., 1988; Carette et al., 1994), FM continues to defy understanding. For those diagnosed with fibromyalgia, there is a deeply felt contraindication between the subjective certainty of their symptoms and the inability of biomedical science to demonstrate an objective existence. This results in self-doubt and alienation among sufferers. Patients experience frustration in that they have to make an effort to convince doctors of their symptoms. The quality of life, mood, anxiety, depression, and self-esteem have been reported a negative impact on FM patients (Wolfe et al., 2013). Therefore, it is imperative that FM patients' experiences be explored to provide better care. The purpose of this study was to explore the life experience of Taiwanese women with FM in order to gain knowledge which can contribute to increased quality of care for oriental people. 


\section{Methodology \\ Design}

Qualitative study with in-depth interviews was used for this study. Qualitative study of subjective experiences and common dialogue of women's story-telling was appropriate in this study because it captured with authenticity the opinions and responses of the participants (Clandinin, 2007). It has proven to be a useful method in previous studies of patients' expectations (Kenten, Bowling, Lambert, Howe, \& Rowe, 2010). Taiwanese women met the following criteria: (a) born and live in Taiwan; (b) diagnosed by a doctor as having fibromyalgia; (c) speaking Mandarin or Taiwanese; (d) no learning, hearing, or communication difficulties; (e) willingness to participate were recruited in this study.

\section{Setting and Samples}

This study took place in Northern part of Taiwan. Participants were contacted by researchers to arrange the interview appointments. Each interview was conducted at times convenient and preference for the participants. Interview sites were arranged for participants' convenience while insuring privacy and confidentiality in order to facilitate participants' exploring their experiences or/and feelings. For example, the interview site was in a private quiet place chosen by participants or in their house. We recruited a purposive sample of 19 women.

\section{Ethical Considerations}

This study was approved by the Research Ethics Committee of both the university and one medical center in northern Taiwan. Women who were interested in participating in this research received explanation regarding the purpose of the study and were given written informed consents. Most interviews were conducted in a private room in the hospital or in the participant's home to ensure that participants were comfortable. This better facilitated the exploration of the participant's experiences and feelings. All participants were ensured that their data would be treated anonymously and were allowed to withdraw from the study at any time during the interview.

\section{Data Collection}

Participants of this study were recruited from a rheumatology outpatient clinic, psychiatric outpatient clinic, and the snow-ball method. Each participant was interviewed approximately 40 to 120 minutes. These interviews were audio-taped and transcribed verbatim immediately following each interview. The researcher clarified the meaning of the interview content via telephone during data analyses. The interview began with: "Can you tell me how you know you have FM?" "Before you were diagnosed with FM, what 
other diagnosis did you receive?" "What kind of tests did you have?" "Can you describe to me how you manage a whole day?" When the data was saturated, that is, when incoming responses presented themes already sufficiently dealt with in previous contributions and no new categories emerged, the interview stopped.

\section{Data Analysis}

All participants were audio-taped. Recordings were then transcribed into written form so that they could be studied in detail, linked with analytic notes and/or coded (Have, 2007). The researcher constantly compared data that revealed the properties and dimensions of categories (Silverman, 2013; Strauss \& Corbin, 1990) with the aid of a senior nursing specialist analyst. Data were analyzed by using four criteria regarding trustworthiness of qualitative research to evaluate the rigor of the study: (a) true value; (b) applicability; (c) consistency; (d) neutrality (Lincoln \& Guba, 1985). To ensure the truth value or credibility of this study, credibility was established by utilizing open-ended questions, and verifying whether the researcher heard the participant's responses correctly. Regarding applicability, the characteristics of participant were of great range and variation. During data collection and analysis, the researcher and the senior nursing expert constantly compared, recoded, confirmed, and reconfirmed to establish consistency. Finally, neutrality was attained through audio-taping and summary notes, which were written the same day.

\section{Results}

A total of nineteen women who met the inclusion criteria and participated in the in-depth interviews were recruited in this study. The average age of the participant was 47.3 years (range from 22 to 62 years). There were 8 women with full time job, 3 women with part-time job, and 8 women with no job. The average duration of symptoms and time of diagnosis were 12.8years (range from 1 to 38 years) and 3.5years (range from 0 to 12years). The demographic and clinical characteristics of women are shown in Table 1.

Table 1. Demographic and Clinical Characteristic of Women with Fibromyalgia

\begin{tabular}{cccccc}
\hline Order & $\begin{array}{c}\text { Age } \\
\text { (years) }\end{array}$ & Education & Work Status & $\begin{array}{c}\text { Duration of } \\
\text { Symptoms } \\
\text { (years) }\end{array}$ & $\begin{array}{c}\text { Years Since } \\
\text { First } \\
\text { Diagnosis }\end{array}$ \\
\hline & & high school & no job & 4 & 2 \\
1 & 52 & elementary & no job & 8 & 4 \\
2 & 62 & elementary & full time & 8 & 1 \\
3 & 47 & high school & no job & 38 & 1 \\
4 & 52 & elementary & no job & 12 & 1 \\
5 & 61 & none & no job & 6 & 1 \\
6 & 50 & & &
\end{tabular}




$\begin{array}{cccccc}7 & 51 & \text { high school } & \text { no job } & 11 & 10 \\ 8 & 50 & \text { middle school } & \text { full time } & 30 & 1 \\ 9 & 40 & \text { high school } & \text { part time } & 7 & 7 \\ 10 & 22 & \text { college } & \text { part time } & 7 & 3 \\ 11 & 41 & \text { high school } & \text { no job } & 16 & 1 \\ 12 & 42 & \text { college } & \text { full time } & 26 & 12 \\ 13 & 54 & \text { masters degree } & \text { full time } & 1 & 1 \\ 14 & 50 & \text { masters degree } & \text { full time } & 5 & 5 \\ 15 & 50 & \text { college } & \text { full time } & 5 & 2 \\ 16 & 21 & \text { college } & \text { no job } & 7 & 1 \\ 17 & 39 & \text { college } & \text { part time } & 15 & 8 \\ 18 & 60 & \text { college } & \text { full time } & 1 & 0 \\ 19 & 55 & \text { high school } & \text { full time } & 36 & 6\end{array}$

The qualitative data analysis revealed four identified categories: life torture by physical suffering, torment in the mind, treatment seeking and shopping, and facing an incurable and unknown illness alone. Each category is described in terms of its properties and sub-categories in Table 2.

Table 2. Categories and Sub-categories of Taiwanese

Women Who Have Had Experiences with Fibromyalgia

\begin{tabular}{cc}
\hline Category & Sub-category \\
\hline Life torture by Physical Suffering & $\begin{array}{c}\text { Severe pain for the entire body } \\
\text { Lying on the bed often }\end{array}$ \\
Doing nothing left one feeling exhausted \\
Tension of daily living \\
Torment in the Mind \\
Being misunderstood or mistreated \\
Unknown fear or panic \\
Being stigmatized - visiting a psychiatrist for \\
my illness \\
Having suicidal thoughts \\
Visiting a lot of doctors and therapists \\
Tests - no findings, a lot of possible diagnoses \\
Trying Chinese Alternative Medicine \\
Final destination - Psychiatrist
\end{tabular}

Facing An Incurable and Unknown Illness Alone
Put away any other life events, focusing on myself

Self-endurance without bothering others

Self-striving for keeping a job

\section{Life Torture by Physical Suffering}

People with fibromyalgia hurt all over. Their entire body aches. Even more, they have overwhelming fatigue. They are exhausted and do not sleep well at night. There are four sub-categories emerging from the life torture by 
physical suffering: severe pain for the entire body, lying on the bed often, doing nothing left one feeling exhausted, and tension of daily living.

\section{Severe pain for the entire body}

Pain at multiple sites is a major complaint in fibromyalgia patients. The pain is intolerable. All of the women reported that they had multiple severe pains throughout their entire body. One woman responded, "I had pain over my entire body. It was very uncomfortable and like a living death. I couldn't lie down or sit down. I didn't know how to position myself. It started from my shoulders and then ran to my neck, back, hands, and feet. I just felt pain over my entire body."

\section{Lying on the bed often}

Fibromyalgia patients have long term non-restorative sleep. They can't improve their fatigue by sleeping. One woman said, "I felt like I had not slept for nearly one week. I just laid on the bed tossing and turning all night then fell asleep for less than one hour." Another woman said, "I know I had slept but still felt very tired. I just couldn't fall asleep. I changed to a tummy sleeping position or knee down tummy sleeping position but I still couldn't sleep."

\section{Doing nothing left one feeling exhausted}

Fibromyalgia patients have long term fatigue symptoms with pain in the body. It's like profound exhaustion and poor stamina. One woman said, "I felt my shoulders collapse. I didn't want to do anything such as shopping or talking to anyone. I didn't want to move, but just wanted to close my eyes and rest." Another woman said, "I didn't have energy to do anything. I didn't want to move; even walking made me feel tired. .....I went to bed and laid there doing nothing. My house was a mess and I couldn't do anything about it."

\section{Tension of daily living}

Lack of strength with profound pain set limitations on FM women's daily life, yet they still had to keep things going. Getting rest was next to impossible. One woman said, "I knew I was weaker than before and could not do as much house work. I worried a lot when I was alone about managing the household while my husband was on a business trip. I needed to get up early to prepare things for my kids. After work, I needed to rush to kids' tutoring class and pick them up. There was no time to relax even though I felt my body falling apart. I needed to endure all these things by myself." 


\section{Torment in the Mind}

This category refers to the participants who had suffered mentally and emotionally. With only subjective descriptions and no objective data, fibromyalgia patients experienced frustration, feeling lonely, and a sense of helplessness due to the fact that they needed to make an effort in order to be believed. From the perspective of mental suffering, several areas of content emerged to form the following sub-categories: being misunderstood or mistreated, unknown fear or panic, being stigmatized-visiting a psychiatrist for my illness, and having suicidal thoughts.

\section{Being misunderstood or mistreated}

Without objective tests available and a lack of abnormalities on a physical examination for diagnosing fibromyalgia, some health care professionals do not believe a patient's complaints. In the meantime, people around them could not understand why a healthy-looking person could be too sick to do housework or participate in ordinary activities. Comments received from the participants are as follows: "I can't plan anything in advance and I don't go out with my friends anymore because I have to cancel at the last minute and my friends don't understand why. I really didn't want to break my promise but I had no choice." "The doctor who I went to said that after all these tests, he didn't find anything wrong with me. He didn't think I had a problem. He prescribed pain killers for me and suggested I see a psychiatrist."

\section{Unknown fear or panic}

After seeing different doctors for many years without any improvement of their symptoms, patients became easily panicked. Responses include: "When sitting alone with all this discomfort, I felt unexplained panic. I was afraid something bad was growing in my body, which exacerbated my sleep disorder. I worried about a lot of things which caused panic." "I was awakened by severe pain and got very nervous. All of a sudden I panicked for no reason. I felt horrible. I just felt very uncomfortable throughout my entire body and would start crying."

\section{Being stigmatized - visiting a psychiatrist for my illness}

Many times, women with FM were hesitant to tell people they were seeing a psychiatrist for fear people would think they were crazy. They felt it was shameful to have this disorder and to see a psychiatrist. Some of the comments received are as follows: "I was so afraid of letting my friends know. I felt it was shameful. I forced myself to act like a normal person so others would not identify my disorder. I didn't want them to think I was an abnormal person." "I didn't want my villagers to know that I went to see a psychiatrist; 
I felt shameful as well as laughed at by them. I did not want to be tagged as someone who saw a psychiatrist."

\section{Having suicidal thoughts}

After the hopelessness of visiting one physician after another and being treated improperly and misunderstood, suicidal thoughts entered some FM patient's minds. One woman reported, "I was so disappointed about the treatment I received. I just gave up. Sometimes I asked myself why I should live such a miserable life. I suffered so much and grew tired of living with FM. I lived like I wasn't alive. So, I had suicidal thoughts." Another woman said, "When I was in severe discomfort I thought about suicide. I didn't want to be alive. Every time I was lying on the bed, I thought about not waking up. I wanted to just lie there forever."

\section{Treatment Seeking}

Unlike in the United States, there is no specific clinic for fibromyalgia patients in Taiwan. Taiwanese people visit different specialists based on their symptoms. Most of the doctors could not resolve their symptoms or give proper diagnoses. As a result, patients had to keep visiting different specialists. The sub-categories included visiting a lot of doctors and therapists, unknown fear or panic, being stigmatized - visiting a psychiatrist for my illness, and having suicidal thoughts.

\section{Visiting a lot of doctors and therapists}

Fibromyalgia is not well understood by most people. Before being diagnosed with fibromyalgia, most women went to different areas of specialty associated with their symptoms such as orthopedics, rehabilitation, neurology, Chinese medicine, etc. The doctors can only treat the symptoms. Often, inappropriate treatments and/or procedures were ordered. One woman reported, "At the beginning, I thought it was a nerve problem, so I went to see a neurologist. When that didn't work, they changed course and I saw an orthopedist. The orthopedist gave me an injection which lasted for a while. But again, it didn't work. I grew tired of seeing doctors." Another woman said, "I went to see Dr. Hsiao (psychiatrist). I had visited a lot of other specialists which proved worthless. I visited a cardiologist, a neurologist, and an internist. Finally, I went to a psychiatrist and was treated with kindness and effectiveness."

\section{Tests - no findings, a lot of possible diagnoses}

Before getting the correct diagnoses, doctors have to rule out similar diseases such as lupus or rheumatoid arthritis. Therefore, fibromyalgia women had to undergo all kinds of tests. One woman said, "I first went to a rheumatologist and he suspected I had arthritis. He did all the tests but found 
nothing. Then I went to a neurologist and he did different tests for my entire body and found nothing wrong with me."

\section{Trying Chinese Alternative Medicine}

Since there is limited effect on treatment with conventional medicine, some women with FM seek Chinese alternatives. Reports from women include: "I tried a Chinese massage therapist a couple of times, but didn't feel a difference. So I tried an acupuncturist for several weeks and didn't feel any effects. I would rather take pain killers." "I began doing scraping therapy (Guasha) whenever I had pain. In addition to scraping, I massaged the pain area and then put on a pain-relieving patch. Sometimes I did cupping but felt scraping was better than cupping."

\section{Final destination - Psychiatrist}

After seeing all kinds of specialists in vain, women with fibromyalgia were referred to a psychiatrist. One woman responded, "I saw an orthopedist and a neurologist on and off for a while without results. The neurologist suggested I see a psychiatrist." Another woman said, "My cardiologist referred me to Dr. Hsiao (psychiatrist). At the time, no one could tell me what was wrong with me. I was just attacked by the symptoms. After seeing several doctors, I was referred to a psychiatrist."

\section{Facing an Incurable and Unknown Illness Alone}

As with many other medically unexplained syndromes, there is no known cure or universally accepted treatment for fibromyalgia. The treatment of fibromyalgia is complex and long-term. Being in pain everyday made women with FM irritable and sometimes negatively affected their family members and/or their jobs. Therefore, patients with fibromyalgia needed to find their own way to face or resolve the discomforts.

\section{Put away any other life events, focusing on myself}

Taiwanese women with FM spent a great amount of time taking care of people around them. They learned to endure the discomforts of their illness. Sometimes their family would remind them to put away life events and focus on themselves. They realized the importance of this. One woman said, "My husband helped me. He did not want to see me suffering. If there was something concerning the kids that he could handle, he would ask me to go away and he would deal with the kids or ask the kids to go to the other room so I could relax." Another woman said, "I needed to start doing things independently. I needed to learn not to be influenced by other people or to influence other people due to my illness. I needed to constantly remind myself 
to relax. I told myself and my husband that I wanted to get well. I desired his cooperation."

\section{Self-endurance without bothering others}

Taiwanese women with FM tolerated their illness by hiding their discomforts. One woman said, "My husband knew my symptoms well but sometimes grew tired of my complaints. Hence, I got angry and quarreled with him. This drove me not to tell him how bad I was feeling. Even when I was in such pain, I just suppressed it and continued doing the housework. I knew he would be unhappy if I complained." Another woman said, "I lived with my mother-in-law who was a very traditional woman. My mother-in-law had all the authority in the house. She asked me to take care of the kids and to do all the housework by myself. I was not allowed to use the washing machine to wash the kids' clothes even when I was in such pain. Sometimes I even felt my body was falling apart. My husband could not help me if my mother-inlaw was present. I just buried all my discomforts and feelings and did what my mother-in-law wanted me to do."

\section{Self-striving for keeping a job}

Even with physical discomfort and impaired concentration, some women with fibromyalgia tried very hard to keep their jobs. This enabled them to continue raising their kids and manage their household expenses. Some women reported: "Fibromyalgia influenced my work when I was at the office. I would not let anybody know about my disease. I just tolerated it as much as possible. If necessary, I would take sick leave and go to the hospital." "The biggest change of my life was leaving the work I loved. I was forced to leave my work due to poor performance. Then I sought a new job and ended up quitting it later. It was an endless cycle. When I was in pain while working, I just gritted my teeth and endured it or took pain killers. I eventually quit my job. Most of the time, I had to stay home with no outside employment."

\section{Discussion}

This study has demonstrated the experiences of women with fibromyalgia from a qualitative perspective including life torture by physical suffering, torment in the mind, treatment seeking and shopping, and facing an incurable and unknown illness alone. Discussion of the impact of findings in relation to other studies, strengths, and limitations are included.

Pain is the most distinguishing symptom in FM patients. In this study, pain, as a constant presence, was a prominent factor throughout. All participants described a certain degree of chronic widespread body pain. This result is consistent with two research articles (Arnold et al., 2008; Lempp, Hatch, Carville, \& Choy, 2009)(Lempp, Hatch, Carville, and Choy, 2009, 
Arnold, et al. 2008). In Lempp's (Lempp et al., 2009)(2009) study, pain was a common description in most of the participants. Arnold et al. (Arnold et al., 2008)(2008) found that all participants expressed living with constant pain and described their inability to pinpoint the exact source or location of their pain.

In addition to the pain endured, participants in this study described intense sleep disorder. They complained of having difficulty getting to sleep or of waking up constantly throughout the night. This finding was similar to the Soderberg (Söderberg, Lundman, \& Norberg, 2002) (2002) study under the subtheme - a feeling of almost constant sleepiness. This was described as not being thoroughly rested and not being fully awake (Söderberg et al., 2002)(Soderberg, Lundman, \& Norberg, 2002). Lempp (Lempp et al., 2009)(2009) also found out that all participants in the study complained about the lack of restful sleep over years resulting in chronic fatigue for half of them.

The fatigue in women with FM was much more than being tired after a sleepless night. It was a profound exhaustion. In this current study, participants felt tired and had no energy to do anything at all, which also affected their daily life. The same findings are found in the studies of Schoofs (Schoofs, Bambini, Ronning, Bielak, \& Woehl, 2004) and Arnold et al.(Arnold et al., 2008).

Even while suffering from so many discomforts such as pain, sleeplessness, and fatigue, women with FM still wanted to maintain the lives they lived prior to FM. Therefore, much effort was put into keeping the home tidy and neat, and satisfying others' needs. This contributed to flare-ups of their symptoms. They felt frustrated with the lack of control of their lives.

As far as mental suffering, participants in this study described that many health care providers lacked FM knowledge concerning their condition. Many did not believe the symptoms were present. Therefore, the healthcare providers demonstrated low health care support. In addition, their family and/or friends could not understand why a healthy-looking person could be so sick. These findings were similar to studies (Henriksson \& Burckhardt, 1996; Mengshoel \& Heggen, 2004; Schoofs et al., 2004) which showed that physicians, friends, colleagues, and family members had a clear tendency to doubt the reality of their experience or that the doctor lacked knowledge and had difficulties explaining the symptoms.

Before getting a diagnosis, FM patients had to seek many health care providers for an official diagnosis. This finding was supported by another study (Schoofs et al., 2004). The major difference was that Taiwanese women sought out Chinese medicine since it was easier to access. By suffering symptoms for so many years, FM patients became depressed or even had suicidal thoughts. This was because they felt misunderstood by health care providers, or by family and friends. As we know that FM is associated with depression and anxiety (Krag, Norregaard, Larsen, \& Danneskiold-Samsoe, 
1994), the presence of a co-existing psychiatric disease may increase the severity of FM symptoms by lowering one's pain threshold and tolerance.

Taiwanese women with FM were hesitant to tell people that they had been seeing a psychiatrist for treatment. They felt it meant they were crazy and they felt shame. This finding was similar to studies (Schaefer, 2005; Undeland \& Malterud, 2007) which showed women with FM often chose to keep their diagnosis a secret because of others' reaction to their illness that everything was in their head. It was easier than trying to explain something to someone who could not see the illness or who did not believe they were truly ill.

In order to provide better quality care to women with FM, health care providers should take FM seriously, admit what they don't know, study to find out what helps FM patients, and be willing to treat individuals uniquely, listen to patients, and learn from them. In addition, they should believe their patients, take the patient's concerns seriously so they don't have to exaggerate, and be willing to use alternative and complementary therapies if the patient wants to try them and they won't be harmful. The health care provider should help the patient understand that there is no cure for FM and they must learn to live with it. They must be partners with the patient in health care provision and they must be compassionate.

For women with FM, exercise will help with stress and improve sleep, as well as help maintain strength, balance, and flexibility. Pacing oneself is the key to managing FM symptoms. Intervention includes: knowing your body, short activity periods, scheduled rest, routines, prioritizing, and switching tasks. Due to cultural differences, women in Taiwan endure and suppress the pain. They feel it is not appropriate to talk about their pain in public. Therefore, they need to be encouraged to express their feelings verbally.

\section{Conclusion}

From literature review, most studies are focused on effectiveness of intervention such as acupuncture, Tai Chi exercise, yoga exercise, aquatic therapy, etc. Little research has been done in qualitative study on the exploration of FM experiences in Taiwan. It is important to hear the experience of FM patients so as to provide better quality of care. Without hearing their heartfelt wishes, it is hard to design effective intervention from their perspectives.

It is important that women with FM be encouraged to speak out. With the results of this study, the information can provide health care providers a better understanding of FM patients especially for Asian population. In the meantime more health care providers including physicians and nurse should 
be trained to treat FM patients with empathy. Pain is a subjective feeling and needs to be paid attention to and addressed.

\section{References:}

1. Arnold, L. M., Crofford, L. J., Mease, P. J., Burgess, S. M., Palmer, S. C., Abetz, L., \& Martin, S. A. (2008). Patient perspectives on the impact of fibromyalgia. Patient Education \& Counseling, 73(1), 114120. doi: 10.1016/j.pec.2008.06.005

2. Bennett, R. M., Gatter, R. A., Campbell, S. M., Andrews, R. P., Clark, S. R., \& Scarola, J. A. (1988). A comparison of cyclobenzaprine and placebo in the management of fibrositis. A double-blind controlled study. Arthritis Rheum, 31(12), 1535-1542.

3. Bennett, R. M., Jones, J., Turk, D. C., Russell, I. J., \& Matallana, L. (2007). An internet survey of 2,596 people with fibromyalgia. $B M C$ Musculoskeletal Disorders, 8, 27-11. doi: 10.1186/1471-2474-8-27

4. Carette, S., Bell, M. J., Reynolds, W. J., Haraoui, B., McCain, G. A., Bykerk, V. P., . . . et al. (1994). Comparison of amitriptyline, cyclobenzaprine, and placebo in the treatment of fibromyalgia. A randomized, double-blind clinical trial. Arthritis Rheum, 37(1), 32-40.

5. Chandran, A., Schaefer, C., Ryan, K., Baik, R., McNett, M., \& Zlateva, G. (2012). The comparative economic burden of mild, moderate, and severe fibromyalgia: results from a retrospective chart review and cross-sectional survey of working-age U.S. adults. Journal of Managed Care Pharmacy: JMCP, 18(6), 415-426.

6. Chen, J., Guo, M., You, Y., Liaw, L., \& Kuo, H. (2008). Factors affecting Fibromyalgia in Nantou County. Mid-Taiwan Journal of Medicine, 13, 136-142.

7. Clandinin, D. J. (2007). Handbook of narrative inquiry : mapping a methodology. Thousand Oaks, Calif.: Sage Publications.

8. Giesecke, T., Williams, D. A., Harris, R. E., Cupps, T. R., Tian, X., Tian, T. X., . . . Clauw, D. J. (2003). Subgrouping of fibromyalgia patients on the basis of pressure-pain thresholds and psychological factors. Arthritis Rheum, 48(10), 2916-2922. doi: 10.1002/art.11272

9. Goldenberg, D., Schaefer, C., Ryan, K., Chandran, A., \& Slateva, G. (2009). What is the true cost of fibromyalgia to our society: results from a cross-sectional survey in the United States. Arthritis Rheum, 60(supplement 10), 104.

10. Goldenberg, D. L. (1995). Fibromyalgia: why such controversy? Ann Rheum Dis, 54(1), 3-5.

11. Gota, C. E., Kaouk, S., \& Wilke, W. S. (2015). Fibromyalgia and Obesity: The Association Between Body Mass Index and Disability, 
Depression, History of Abuse, Medications, and Comorbidities. J Clin Rheumatol, 21(6), 289-295. doi: 10.1097/rhu.0000000000000278

12. Have, P. (2007). Doing Conversation Analysis: SAGE Publications.

13. Henriksson, C., \& Burckhardt, C. (1996). Impact of fibromyalgia on everyday life: a study of women in the USA and Sweden. Disabil Rehabil, 18(5), 241-248.

14. Kenten, C., Bowling, A., Lambert, N., Howe, A., \& Rowe, G. (2010). A study of patient expectations in a Norfolk general practice. Health Expectations, 13(3), 273-284. doi: 10.1111/j.1369-7625.2010.00603.x

15. Kim, C., Kim, H., \& Kim, J. (2012). Prevalence of chronic widespread pain and fibromyalgia syndrome: a Korean hospital-based study. Rheumatology International, 32(11), 3435-3442. doi: 10.1007/s00296-011-2195-1

16. Krag, N. J., Norregaard, J., Larsen, J. K., \& Danneskiold-Samsoe, B. (1994). A blinded, controlled evaluation of anxiety and depressive symptoms in patients with fibromyalgia, as measured by standardized psychometric interview scales. Acta Psychiatr Scand, 89(6), 370-375.

17. Lempp, H. K., Hatch, S. L., Carville, S. F., \& Choy, E. H. (2009). Patients' experiences of living with and receiving treatment for fibromyalgia syndrome: a qualitative study. BMC Musculoskeletal Disorders, 10, 124-124. doi: 10.1186/1471-2474-10-124

18. Lincoln, Y. S., \& Guba, E. G. (1985). Naturalistic Inquiry: SAGE Publications.

19. Mengshoel, A. M., \& Heggen, K. (2004). Recovery from fibromyalgia -- previous patients' own experiences. Disability \& Rehabilitation, 26(1), 46-53.

20. Nakamura, I., Nishioka, K., Usui, C., Osada, K., Ichibayashi, H., Ishida, M., .. . Nishioka, K. (2014). An epidemiologic internet survey of fibromyalgia and chronic pain in Japan. Arthritis Care \& Research, 66(7), 1093-1101. doi: 10.1002/acr.22277

21. Söderberg, S., Lundman, B., \& Norberg, A. (2002). The meaning of fatigue and tiredness as narrated by women with fibromyalgia and healthy women. Journal of Clinical Nursing, 11(2), 247-255. doi: 10.1046/j.1365-2702.2002.00606.x

22. Schaefer, K. M. (2005). The lived experience of fibromyalgia in African American women. Holist Nurs Pract, 19(1), 17-25.

23. Schoofs, N., Bambini, D., Ronning, P., Bielak, E., \& Woehl, J. (2004). Death of a lifestyle: the effects of social support and healthcare support on the quality of life of persons with fibromyalgia and/or chronic fatigue syndrome. Orthopaedic Nursing, 23(6), 364-374.

24. Silverman, D. (2013). Doing qualitative research: A practical handbook: SAGE Publications Limited. 
25. Strauss, A. L., \& Corbin, J. M. (1990). Basics of qualitative research: grounded theory procedures and techniques: Sage Publications.

26. Toda, K. (2007). The prevalence of fibromyalgia in Japanese workers. Scand J Rheumatol, 36(2), 140-144. doi: 10.1080/03009740600907949

27. Undeland, M., \& Malterud, K. (2007). The fibromyalgia diagnosis hardly helpful for the patients? Scandinavian Journal of Primary Health Care, 25(4), 250-255.

28. Walitt, B., Katz, R. S., Bergman, M. J., \& Wolfe, F. (2016). ThreeQuarters of Persons in the US Population Reporting a Clinical Diagnosis of Fibromyalgia Do Not Satisfy Fibromyalgia Criteria: The 2012 National Health Interview Survey. PLoS One, 11(6), e0157235. doi: 10.1371/journal.pone.0157235

29. Walitt, B., Nahin, R. L., Katz, R. S., Bergman, M. J., \& Wolfe, F. (2015). The Prevalence and Characteristics of Fibromyalgia in the 2012 National Health Interview Survey. PLoS One, 10(9), e0138024. doi: 10.1371/journal.pone.0138024

30. Wassem, R., \& Hendrix, T. J. (2003). Direct and indirect costs of fibromyalgia to patients and their families. Journal of Orthopaedic Nursing, 7(1), 26-32.

31. Wolfe, F. (2009). Fibromyalgia wars. Journal of Rheumatology, 36(4), 671-678. doi: 10.3899/jrheum.081180

32. Wolfe, F., Brähler, E., Hinz, A., \& Häuser, W. (2013). Fibromyalgia prevalence, somatic symptom reporting, and the dimensionality of polysymptomatic distress: results from a survey of the general population. Arthritis Care \& Research, 65(5), 777-785. doi: 10.1002/acr.21931

33. Wolfe, F., Clauw, D. J., Fitzcharles, M.-A., Goldenberg, D. L., Häuser, W., Katz, R. S., . . . Winfield, J. B. (2011). Fibromyalgia criteria and severity scales for clinical and epidemiological studies: a modification of the ACR Preliminary Diagnostic Criteria for Fibromyalgia. Journal of Rheumatology, 38(6), 1113-1122. doi: 10.3899/jrheum.100594

34. Wolfe, F., Clauw, D. J., Fitzcharles, M. A., Goldenberg, D. L., Katz, R. S., Mease, P., . . . Yunus, M. B. (2010). The American College of Rheumatology preliminary diagnostic criteria for fibromyalgia and measurement of symptom severity. Arthritis Care \& Research, 62(5), 600-610. doi: 10.1002/acr.20140 